\title{
Transition Experiences of Newly Graduated Nurses
}

\author{
Cennet Ciris Yildiz (D), Yasemin Ergun (iD) \\ Marmara University, Faculty of Health Sciences, Department of Nursing, Istanbul, Turkey. \\ Correspondence Author: Cennet Ciris Yildiz \\ E-mail: cennet_ciris@hotmail.com \\ Received: $08.08 .2019 \quad$ Accepted: 22.11.2019
}

\begin{abstract}
Objective: This is a qualitative study based on content analysis in order to reveal the transition experiences of nurses in the first year of their profession.

Methods: The study was carried out between January 2018 and March 2018 with 30 newly graduated nurses, who work in three Training and Research Hospitals, two University Hospitals and three Private Hospitals with JCl Quality Certificate and have a maximum of one year of professional experience. Data were collected through semi-structured in-depth individual interviews using face-to-face interviews.

Results: Themes defined in the transition process of newly graduated nurses were emotional, sociocultural and developmental, physical and intellectual. In general, transition experiences of individuals were greatly influenced by the support that is given to the new graduate, the experience, the predictability, sincerity and consistency of the relationships with the individuals they were in contact with, and the expectations of the institution or experienced employees. In the first year of their professional experience, graduates do not feel themselves qualified, comfortable, safe and secure, and experience emotional and physical exhaustion in a short time. In addition, changes in life patterns and routines have emerged as distracting developments or unexpected burdens, particularly for new graduates experiencing adaptation problems. Conclusion: This study focused on the experiences of nurses during their first-year practice which is incredibly challenging for the new graduated nurses. It has been determined that formal and informal support programs are necessary for the new graduates to successfully start the profession.
\end{abstract}

Keywords: Nurse, Nursing Staff, Nurse's Scope of Practice, Transition

\section{INTRODUCTION}

The transition from professional education program to the profession was considered as a stressful period involving adaptation difficulties $(1,2)$. This is because new graduates join the work environment without feeling ready. Especially nurses are required to adapt to the working conditions as soon as possible due to reasons such as lack of nurse workforce and to have the necessary knowledge, skills and confidence (3). The newly graduated nurses undergo a number of developmental stages depending on the difficulties they face during the transition process. Duchsher (3) found that newly graduated nurses were selfish and independent in the first few months of their professional experience; that nurses felt safer and more self-confident between the 2 nd and 3 rd months; and that nurses developed critical thinking skills and started to work independently in the 5th month. Mckenna and Green (4) found that nurses tried to adapt to the profession and focused on themselves in the first 6 months of the transition period. They stated that the nurses focused on the larger picture such as patient care, relationships and their continuing development in the second 6 months of the transition period (4).

Initially, the newly graduated nurse tries to accept it when she encounters a new workplace culture. But in this process the nurse is likely to be uncomfortable and may experience a feeling of inadequacy. The new graduate experiences the shock of reality created by a clash of ideal and value when she moves to a culture that is often different from the culture, she comes from by gaining certain values and ideals. In some cases, reactions to inequality between expectations and reality are so great that individuals cannot cope with this situation (1). The entry of the new graduate into the work area with such an attitude and behavior is a clear indication that she is poorly prepared for the work area. It is inevitable that individuals who are equipped with non-realistic skills, technical knowledge, non-role-specific behaviors and who do 
not have real values related to work will experience serious role conflict $(1,5)$. Duchsher $(6)$ states that newly graduated nurses experience "awareness of the truth", "frustration" and "disassociation" because they encounter inconsistency between theory and practice environment. In addition, some studies have shown that newly graduated nurses experience different problems such as anxiety, tension, fear, panic and burnout in the first years of transition to the profession and these problems endanger their physical and mental health, accelerate the employee turnover rate (6).

The high turnover rate of nurses brings additional financial burden to both the hospital and the national economy. Kelly and Ahern (7) stated that in the first year of employment, the cost of turnover rate of newly graduated nurses represented a loss of approximately $\$ 40,000$, including hiring and orientation costs. It was found that medical errors increased, and the quality of care decreased in the newly graduated nurses due to the problems experienced during the transition process.

Present study was carried out in order to reveal the transition experiences of nurses in the first year of their profession, because of the importance of the subject in terms of nursing services, health institutions and vocational education institutions, and due to the limited number of studies on transitional experience at national level.

\section{METHODS}

\subsection{Design and participants}

The participants of the study consisted of the nurses with bachelor's degree, who work in three Training and Research Hospitals, two University Hospitals and three Private Hospitals with $\mathrm{JCl}$ Quality Certificate in Istanbul's Anatolian side and have a maximum of one year of professional experience.

In the study, maximum diversity sampling method, which is one of the purposeful sampling methods that maximally reflect the diversity of individuals who can be a party to the study, was used. In addition, for sampling, attention was paid to select the participants that differ in terms of the aspects such as school that was graduated from, the hospital/unit that was worked for, and gender. As a result of repeated data, data saturation was achieved, and data collection was terminated in thirty interviews.

\subsection{Data collection}

In order to reveal the transition emotions of the nurses in the study, a 40-item open-ended "Semi-Structured Interview Form" was prepared by the researcher based on the "Transition Shock" model developed by Duchsher (6). Data were collected through semi-structured in-depth interviews. The interview form was drawn up on the basis of a review of the literature and contains questions on the participants' reasons for choosing nursing, their expectations after graduation and whether or not these expectations have been met, the difficulties they faced when first hired, the support they have, the ability to apply their training, differences between training and actual practice, satisfaction with work and their intent to leave the profession (1-4). The created questions were then assessed by a faculty member who an expert in the area of qualitative research was. A pilot interview was conducted with 2 nurses with the same characteristics as the interview form sampling group before starting the study. After the pilot application, final arrangements were made regarding the interview form. The answers to the study questions were recorded during the interview. Recorded responses were transferred to computer environment. The interviews were held over the period December 2017-March 2018 following receipt of the needed approvals for the study. An appropriate setting was created for the interviews, which took place either in the department meeting rooms or in nurses' offices. A researcher took part in the interviews. Interviews of approximately 45-150 minutes were conducted with the interviewees. Although some of the participants were promised that their personal details would remain confidential, they were not comfortable during their assessment of their institution. During the interviews, length of some interview was long in order to make participants feel comfortable and to obtain detailed information.

\subsection{Ethical considerations}

Prior to the study, written and verbal permissions were obtained from the Clinical Research Ethics Committee (Marmara University Faculty of Medicine Clinical Research Committee - Date: December 03, 2017 - No: 09.2017.668) and hospital management. Each participant was informed about the purpose and method of the study, and an informed consent form was signed indicating that they voluntarily participated.

\subsection{Statistical analysis}

Content analysis and the MAXQDA program was used in the analysis of the data. The data recorded with the device were transferred to the computer, after which the researcher listened to the recordings once again. The report was then revised to ensure a correct rendition of what the participants meant to say. Responses that were meaningful were assigned names/codes. Similar codes appearing in different parts were brought together to form a code list. Examining the similarities and differences between codes led to the designation of themes/subthemes. The themes and subthemes were evaluated by 3 experts who had training in qualitative research and their final construct was created. The data collected in the study were categorized based on Duchscher's (6) "Transition Shock Model" where the categories were delineated as emotional, sociocultural and developmental, physical and intellectual. In this study, consistency formula was used to determine reliability in content analysis. In this study, the agreement percentage was determined as $76 \%$. Descriptive content of the newly graduated nurses was coded by giving numbers like $\mathrm{K} 1$, $\mathrm{K} 2, \ldots . \mathrm{K} 30$, and the findings related to the participants' characteristics are given in Table 1. 
Table 1. Findings on the Identifying Characteristics of the Participants

\begin{tabular}{|c|c|c|c|c|c|c|c|c|}
\hline $\begin{array}{l}\text { Interview } \\
\text { Number }\end{array}$ & Age & Gender & Institution worked & Department worked & Tenure & $\begin{array}{l}\text { Having } \\
\text { orientation } \\
\text { training }\end{array}$ & $\begin{array}{l}\text { Another department/ } \\
\text { institution worked }\end{array}$ & $\begin{array}{c}\text { Intention to } \\
\text { Quit }\end{array}$ \\
\hline K1 & 23 & $\mathrm{~F}$ & Private Hospital & Mixed Surgery & 6 months & 1 month & $\begin{array}{l}2 \text { Months in } \\
\text { Emergency }\end{array}$ & Considering \\
\hline K2 & 24 & $\mathrm{~F}$ & Private Hospital & Cardiology & 8 months & 3 weeks & - & Considering \\
\hline K3 & 23 & $\mathrm{~F}$ & Private Hospital & Intensive Care & 1 year & 1.5 months & - & Considering \\
\hline K4 & 23 & $\mathrm{~F}$ & Private Hospital & Urology & 1 year & 2 months & - & Considering \\
\hline K5 & 23 & $\mathrm{~F}$ & Private Hospital & Operation Room & 6 months & 1 month & 4 months at Pharmacy & $\begin{array}{c}\text { Not } \\
\text { Considering }\end{array}$ \\
\hline K6 & 24 & $\mathrm{~F}$ & Private Hospital & Cardiology & 8 months & 20 days & - & Considering \\
\hline K7 & 25 & $\mathrm{~F}$ & Private Hospital & $\begin{array}{c}\text { Anesthesia Intensive } \\
\text { Care }\end{array}$ & 7 months & 3 days & $\begin{array}{l}8 \text { months in } \\
\text { Gynecology }\end{array}$ & Considering \\
\hline K8 & 24 & $\mathrm{~F}$ & Private Hospital & Pediatric & $\begin{array}{c}11 \\
\text { months }\end{array}$ & 2 months & - & $\begin{array}{c}\text { Not } \\
\text { Considering }\end{array}$ \\
\hline K9 & 24 & $\mathrm{~F}$ & Private Hospital & Mixed Surgery & 6 months & 1 week & $\begin{array}{l}3.5 \text { months in } \\
\text { Gynecology }\end{array}$ & $\begin{array}{c}\text { Not } \\
\text { Considering }\end{array}$ \\
\hline K10 & 25 & M & Private Hospital & Emergency & 3 months & 1 month & - & $\begin{array}{c}\text { Not } \\
\text { Considering }\end{array}$ \\
\hline K11 & 25 & M & Training and Research Hospital & Intensive Care & 7 months & 1 month & $\begin{array}{l}3 \text { months in Internal } \\
\text { Medicines Unit }\end{array}$ & Considering \\
\hline K12 & 24 & $\mathrm{~F}$ & Training and Research Hospital & $\begin{array}{c}\text { Newborn Intensive } \\
\text { Care }\end{array}$ & 6 months & 15 days & - & Considering \\
\hline K13 & 23 & $\mathrm{~F}$ & Training and Research Hospital & Palliative Care & $\begin{array}{c}11 \\
\text { months }\end{array}$ & 10 days & 7 months at LOSEV & Considering \\
\hline K14 & 23 & M & Training and Research Hospital & Ophthalmology & 7 months & 2 weeks & - & $\begin{array}{c}\text { Not } \\
\text { Considering }\end{array}$ \\
\hline K15 & 25 & $\mathrm{~F}$ & Training and Research Hospital & Urology & 3 months & 2 weeks & - & Considering \\
\hline K16 & 24 & $M$ & Training and Research Hospital & Pediatric Emergency & 6 months & 1.5 months & - & Considering \\
\hline K17 & 24 & $\mathrm{~F}$ & Training and Research Hospital & $\begin{array}{l}\text { Newborn Intensive } \\
\text { Care }\end{array}$ & 6 months & 2 months & - & $\begin{array}{c}\text { Not } \\
\text { Considering }\end{array}$ \\
\hline K18 & 22 & $\mathrm{~F}$ & Training and Research Hospital & Hematology & 6 months & 1 week & - & Considering \\
\hline K19 & 22 & $\mathrm{~F}$ & Training and Research Hospital & Internal Medicines & 6 months & 20 days & - & Considering \\
\hline K20 & 23 & $\mathrm{~F}$ & Training and Research Hospital & Orthopedics & 7 months & 3 weeks & - & $\begin{array}{c}\text { Not } \\
\text { Considering }\end{array}$ \\
\hline K21 & 23 & $\mathrm{~F}$ & Training and Research Hospital & Brain Surgery & 4 months & 2 months & - & $\begin{array}{c}\text { Not } \\
\text { Considering }\end{array}$ \\
\hline K22 & 23 & $\mathrm{~F}$ & Training and Research Hospital & Intensive Care & 1 year & 1 month & $\begin{array}{c}2 \text { months in Intensive } \\
\text { Care }\end{array}$ & $\begin{array}{c}\text { Not } \\
\text { Considering }\end{array}$ \\
\hline K23 & 23 & $\mathrm{~F}$ & University Hospital & Perinatology & 1 year & 1 month & - & Considering \\
\hline K24 & 24 & M & University Hospital & Emergency Surgery & $\begin{array}{c}10 \\
\text { months }\end{array}$ & 1 month & - & $\begin{array}{c}\text { Not } \\
\text { Considering }\end{array}$ \\
\hline K25 & 24 & $\mathrm{~F}$ & University Hospital & Otorhinolaryngology & $\begin{array}{c}10 \\
\text { months }\end{array}$ & 2 months & $\begin{array}{c}4 \text { months in Intensive } \\
\text { Care }\end{array}$ & $\begin{array}{c}\text { Not } \\
\text { Considering }\end{array}$ \\
\hline K26 & 24 & $\mathrm{~F}$ & University Hospital & Gynecology-Oncology & $\begin{array}{c}10 \\
\text { months }\end{array}$ & 1 month & - & Considering \\
\hline K27 & 25 & $\mathrm{~F}$ & University Hospital & Pediatric Emergency & $\begin{array}{c}11 \\
\text { months }\end{array}$ & 2 months & $\begin{array}{c}2 \text { months in Intensive } \\
\text { Care }\end{array}$ & $\begin{array}{c}\text { Not } \\
\text { Considering }\end{array}$ \\
\hline K28 & 23 & $\mathrm{~F}$ & University Hospital & $\begin{array}{c}\text { Pediatric } \\
\text { Endocrinology }\end{array}$ & 7 months & 1 month & 3 months in Surgery & $\begin{array}{c}\text { Not } \\
\text { Considering }\end{array}$ \\
\hline K29 & 23 & $\mathrm{~F}$ & University Hospital & Urology & $\begin{array}{c}11 \\
\text { months }\end{array}$ & 1 month & - & Considering \\
\hline K30 & 24 & $\mathrm{~F}$ & University Hospital & Private & $\begin{array}{c}10 \\
\text { months }\end{array}$ & 2 months & $\begin{array}{c}8 \text { months in Intensive } \\
\text { Care }\end{array}$ & Considering \\
\hline
\end{tabular}

F: Female, M: Male 


\subsection{Research limitations}

This study reflects the opinions of newly graduated nurses who participated in the study. Therefore, the results cannot be generalized.

\section{RESULTS}

As a result of the content analysis of the data obtained from the individual in-depth interviews with the newly graduated nurses, the transition experiences of the newly graduated nurses were collected under four main themes. The main themes obtained were: 1 - Emotional, 2 - Physical, 3 Sociocultural and Developmental, 4 - Intellectual.

\subsection{Emotional}

Participants mentioned that they experienced intense emotional fluctuations in the first phase of the transition. Most of the nurses stated that they experienced boredom, stress and occasional physical and psychological weakness in the first year of the transition. The participants expressed their concerns by using the words "I was scared" and "I am sorry".

"... It's been 2 months since I moved to level 2 intensive care. I always monitor the care of the intubated patient... Different nurses performed the same practice in different ways in the unit. I was having trouble with what form of application I should adopt ..." (K17)

"... I have come to understand that there is nothing as bad as for the newly graduated nurse to start in the intensive care unit... On the first day of my employment, patient care responsibility was given, and my patient suffered a cardiac arrest. I could not participate in the heart-lung resuscitation process, I cried, so much so I nearly walked away. I was saying "Find someone else, I cannot do it"... my other friends... they supported me as well... if they hadn't, I probably would have left the profession (K1).

"When I first saw the cardiac arrest, I thought if it happened because of me. In my first shift, I was looking at four elderly patients in their ninety years old.... I had difficulty getting used to. I was very upset, and I was crying constantly when I got home." (K3).

During the transition, the nurses are experiencing intense anxiety about taking the sole responsibility for the entire unit. In particular, it was determined that they spent the time required to sleep and relax by thinking about what might happen in shifts. This causes early burnout in nurses.

"In the past, for example, before I came to the shift, I would lose sleep... When communicating with doctors, for example, I did not know how to communicate with them, nor how to talk with them. I didn't know, for example, how to give blue code, etc., I didn't know where to get it... I was constantly asking at first, I was always ashamed, as if I didn't know anything" (K19).

\subsection{Physical}

The physical responses of the newly graduated nurses during the transition process are emerged due to heavy of the responsibilities.

"... I thought I was very tired during the internships... I was taking home with me someone's responsibility... However, my working life ruined me in 8 months... I came here and there was an intensive tempo; there are days when I come to work every day, sometimes I keep watch and ward in a row, you are getting both mentally and physically tired" (9K).

The nurses stated that their energies are high and willing at the beginning of the adaptation process. However, over time, this excitement gradually decreased, and even some nurses mentioned that they were exhausted in a short time.

"It was very difficult... When I came here, I had a fear inside, I was saying myself 'God, how will I do it?. I found myself in the tempo of working all of a sudden. Go to work in the morning, go out in the evening, get a salary at the end of the month... I have done something, I have achieved something, I was very excited at first and then I got used to the routine... (3K).

Changes in life patterns and routines have emerged as distracting developments or unexpected burdens, particularly for new graduates experiencing adaptation problems.

"Normally when you are in school, you hang out as you wish, you do not go to class if you do not want. No one is expecting too much from you. But once you are graduating, you are laid burdens on you, which are, for example, taking a patient's responsibility, financial support to family members, etc. Is not there a gradual transition to it?" (28K).

During the interviews, it was observed that the new graduates were given excessive role and responsibility without adaptation process. The nurses stated that they experienced physical complaints in a short time depending on the severity of the working conditions. The most common physical disorders are; low back and back pain, getting ill frequently, varicose veins.

"... So the workload is too much... Then constant twentyfour hours of shifts... For example, at eight o'clock in the evening I'll hand over the shift and leave, someone calls saying the service suffers from the lack of personnel, so you will continue the shift, or you are assigned to that service, I was constantly... I was catching a severe flu thrice within two months...." (18K).

\subsection{Sociocultural and developmental}

Being accepted by the team, balancing work and private life and reflecting the education received into practice have been the main socio-cultural and developmental tasks that new graduates perform.

"... Senior nurses want us to learn and practice what they teach at work immediately, when we cannot, they blame us with inadequacy. Although I know everything, including 
diseases, applications, etc., they consider new graduates as novice, and disdain...." (1K).

"My husband says I constantly work every weekend. He is grumbling about why it is always me who is going in the shifts, asking if it is because I am new? ... In the process of adaptation to work life, negative situations may arise in private life. You have to leave your spouse or your mum at home when they are sick. I can't stay with them while they need me... You hate, you can't breathe, but you have to go to work anyway..." (24K).

Professional identity problems, disapproval from the patients or relatives and insecure attitudes caused the new graduate to feel inadequate.

"I was so scared, I didn't want to be seen as a beginner. This time, patients and their relatives were saying 'You are new, you cannot do it, please send someone with experience', when they realized that I was a new graduate. And I had no choice but lying to them, saying that I had already been working for this hospital for 5 years, etc..." (6K).

Developmentally it was important to get feedback from colleagues and managers.

"I was very curious about the evaluations about my work after my shift and how I was, etc... I was just worrying to be not good enough and that they did not tell it to me. After the shift, when my nurse colleagues told me that I was pretty good, I felt relieved..." (27K)

On the other hand, nurses who have started to work in some institutions have adopted a work-centered approach instead of providing quality patient care.

Our teachers would tell us that you would approach the patient holistically at school. They would say that, in the postoperative period, we should check their vital signs at regular intervals... However, the vital signs should be checked every 15 mins., but it is not possible as there are 13 patients, which is too much for us. You are trying to do it in the beginning, but then you lose your motivation and stop taking care of. As the result of such negative experiences, you quit being patient-oriented and take a work-oriented approach..." (24K).

Negative relationships with other professionals in the clinical setting are factors that consume energy and hinder development.

"When I started to work, a few people made me feel like I was new. Initially I felt as if I was working for them... They were harsh like a boss, ordering me to bring this, do that, etc. When I experienced something like that, I held myself back..." (3K).

\subsection{Intellectual}

Some of the participants felt themselves inadequate as a nurse while others stated that they could not transfer the knowledge they learned during their education to practice.
"I have experienced the difficulty of lack of information deeply... Since I did not know anything, I felt inadequate to meet the care needs of the patients. I could not care for all four patients. From the patient's perspective, there could have been a nurse in my place who could give them better care. I am suffering now." (2K).

"I think that I am lack of self-confidence, I'm still nervous while attempting to care for the patient... If I have been unsuccessful in the patient I have undertaken before, I worry that I will fail again.... (26K).

Some of the difficulties that these graduates face in their transition to the profession stem from the approach of senior nurses, clinical trainers and nurse managers towards orientation. As a result, the new graduate is expected to undertake the workload of an experienced practitioner within a few weeks.

In the first month, you attend the orientation training, nobody tells you anything, in the 2nd month, they are trying to teach you, but in the 3rd month, you are now all alone, you are also afraid of asking something, you cannot ask because of the psychology of being considered inadequate, so I did not ask questions unless I am pushed for it..." (18K)

\section{DISCUSSION}

Duchscher (3) has demonstrated that the transition to the profession affects new graduated nurses emotionally. In the study, nurses also stated that their energies were high, and they were eager to work early in the adaptation process. However, over time, this excitement and eagerness have been replaced by physical and psychological burnout. Similarly, Hezaveh et al. (8) found that the stress experienced during the transition to the profession affected nurses physically, emotionally and mentally. Kumaran and Carney (9) found that during the transition period, newly graduated nurses initially felt themselves "excited", "happy", "relaxed", "proud" and "grown up", however, they found that these initial emotions were later replaced by "anger" and "frustration".

One of the main findings of this study was that the needs of newly graduated nurses are different from those of experienced nurses. For example, some newly graduated nurses expect feedback and support from colleagues and managers. Rush et al. (10) suggested that nurses needed formal and informal support in the first 6 to 9 months of professional experience. After starting work, the new graduates are expected to take responsibility of many patients in a short time and to be able to perform unit tasks. Duchscher (3) found that nurses had a "confidence crisis" in the first 5 to 7 months of their professional experience. Gregg et al. (11) revealed that nurses experienced frustration and intense anxiety during the transition period. The reasons for this can be listed as the lack of knowledge and skills, providing unsafe care, and the fear of giving harm to the patient and not being able to cope with responsibilities (3, $10,11)$. In addition, lack of support and negative experiences 
in the work environment can be added to the causes of the anxiety in the study.

Development of the professional identity, being accepted by the team, balancing work and private life and reflecting the education received into practice have been the main socio-cultural and developmental tasks that new graduates perform. Gordon et al. (12) suggested that the new graduate's taking on all roles and responsibilities as a nurse is the main source of stress during the transition period. They demonstrated that consistent support in the clinical setting is important in relieving this stress. Negative relationships with other professionals in the clinical setting are factors that consume energy and hinder development. It takes time for the new graduated to establish professional relationships, learn the norms of the working environment, reflect the education they receive to the practice, and make clinical decisions. In particular, experienced nurses should give time and opportunity to the new graduates and gradually give responsibility (13).

The adaptation of the new graduate to the professional role is achieved through observation within the social networks in the workplace. In particular, as nurses gain confidence in their new roles, they assume more responsibility and manage increasingly complex clinical situations. However, the new graduate's ability to effectively manage the workload and gain the necessary technical skills (13). Gordon et al. (12) emphasized that a new graduated nurse should be taken to the adaptation training in order to work like an experienced nurse and to develop her/his skills. In the study, it was determined that the majority of the nurses received orientation training in the institutions, but some of the difficulties faced by the new graduate in the transition to the profession were caused by the approach of the senior nurses, clinical trainers and nurse managers to the orientation. As a result, the new graduate is expected to undertake the workload of an experienced practitioner within a few weeks. Gordon et al. (12) suggested that new graduate adaptation trainings should be developed and reviewed in order to ensure adaptation of the new graduate to the work environment. Goode et al. (13) stated in their study that the new graduates who started to work in a healthy working environment adapted more quickly and had a lower turnover rate.

The transition from studentship to profession is considered to be stressful not only physically and emotionally, but also socio-culturally and developmentally. Goode et al. (13) found that newly graduated nurses had difficulties in areas such as delegation of authority, setting priorities, managing care, collaborating with other disciplines, conflict resolution and benefiting from feedback. In the studies, it is emphasized that the practice-based education and hospital adaptation programs realized after professional education should be reviewed in terms of content (12-13). These regulations not only reduce the turnover rate of new graduates, but also ensure cost-effectiveness (14). Transition programs that include patient-centered care, quality improvement, evidence-based practice, communication and teamwork, informatics, security, clinical expertise, feedback, reflection, and information have been reported to provide more support to new graduates $(15,16)$.

\section{CONCLUSION}

It was observed that nurses had emotional, physical, sociocultural, developmental and intellectual problems during the transition process. Also, it was determined that while the support provided during the transition process facilitated the transition process of the nurses, however, this support was not sufficient. In particular, the concerns of new graduates need to be paid attention to facilitate the transition. Assessment of nurses' experiences and meeting of their needs in the first years of their professional life will increase the self-confidence and competence of new graduates. In that regard, nurse managers, trainers and researchers have important duties.

Acknowledgment: This article was based on a part of PhD thesis of the first author

\section{REFERENCES}

[1] Kramer M. Reality Shock: Why Nurses Leave Nursing. 1st ed. St Louis: Mosby Company; 1974. pp.3-4.

[2] Oermann MH, Garvin MF. Stresses and challenges for new graduates in hospitals. Nurse Educ Today 2002; 22:225-230.

[3] Duchscher JEB. A process of becoming: The stages of new nursing graduate professional role transition J Contin Educ Nurs 2008; 39(10): 441-450.

[4] McKenna LG, Green C. Experiences and learning during a graduate nurse program: An examination using a focus group approach. Nurse Educ Pract 2004; 4(4):258-263.

[5] Öztürk H, Kurt Ş, Serin GM, Bayrak B, Balık T, Demirbağ BC. Hastanelerde işe yeni başlayan hemşirelerin sorunları. ACU Sağlık Bil Derg 2016; 4:189-201 (in Turkish).

[6] Duchscher JEB. Transition shock: The initial stage of role adaptation for newly graduated Registered Nurses. J Adv Nurs 2009; 65(5):1103-1113.

[7] Kelly J, Ahern K. Preparing nurses for practice: A phenomenological study of the new graduate in Australlia. J Clin Nurs 2009; 18(6):910-918.

[8] Hezaveh MS, Rafil F, Khosravi S, Seyedfatemi N. The experience of stress among new clinical nurses. Nurs Pract Today 2014; 4: 199-206.

[9] Kumaran S, Carney M. Role transition from student nurse to staff nurse: Facilitating the transition period. Nurse Educ Pract 2014; 14(6): 605-611.

[10] Rush KL, Adamack M, Gordon J, Lilly M, Janke R. Best practices of formal new graduate nurse transition programs: An integrative review. Int J Nurs Stud. 2013; 50(3):345-356.

[11] Gregg MF, Wakisaka T, Hayashi C. Nurse managers' strategies for the integration of newly graduated nurses into clinical units in Japan: A qualitative exploratory study. Open Nurs J 2013; 7: 157-164.

[12] Gordon CJ, Aggar C, Williams AM, Walker L, Willcock SM, Bloomfield J. A transition program to primary health care for new graduate nurses: A strategy towards building a 
sustainable primary health care nurse workforce? BMC Nurs 2014; 13(34):2-7.

[13] Goode CJ, Glassman KS, Ponte PR, Krugman M, Peterma T. Requiring a nurse residency for newly licensed registered nurses. Nurs Outlook 2018; 329-332.

[14] Letourneau RM, Fater KH. Nurse Residency Programs: An integrative Review of the Literature. Nurs Educ Perspect 2015; 36(2): 96-101.
[15] Spector N, Blegen MA, Silvestre J, Barnsteiner J, Lynn MR, Ulrich B, Alexander M. Transition to practice study in hospital settings. JNR 2015; 5(4), 24-38.

[16] Silvestre J, Ulrich J, Johnson T, Spector N, Blegen M. A multisite study on a new graduate Registered Nurse transition to practice program: Return on investment. Nurs Econ 2017; 35(3): 110-118.

How to cite this article: Ciris Yildiz C, Ergun Y. Transition Experiences of Newly Graduated Nurses. Clin Exp Health Sci 2020; 10: 113119. DOI: $10.33808 /$ clinexphealthsci. 604266 